\section{Injection of alcohol to control bleeding from ruptured hepatomas}

\author{
S C S Chung, T W Lee, S P Y Kwok, A K C Li
}

Department of Surgery, Prince of Wales Hospital, Chinese University of Hong Kong, Shatin, Hong Kong S C S Chung, MD, senior lecturer

$\mathrm{T} \mathrm{W}$ Lee, MB, medical officer S P Y Kwok, FRCSED, medical officer

A K C Li, MD, professor

Correspondence to: Professor Li.

BrMed $f 1990 ; 301: 421$ successfully treated by injection of alcohol.
Spontaneous haemoperitoneum is an uncommon but dramatic surgical emergency. In areas with a high incidence of hepatoma it often results from rupture of the tumour. ${ }^{1}$ Control of bleeding in such patients is often difficult, and the mortality is high. ${ }^{12}$ We report on three patients with ruptured hepatoma who were

\section{Case reports}

Case 1-A 60 year old woman had a laparotomy for severe abdominal pain and shock, at which 2 litres of blood was drained from the peritoneal cavity. The liver was cirrhotic with an extensive nodular tumour encasing the porta hepatis. The tumour had ruptured with brisk bleeding from a $3 \mathrm{~cm}$ crater. Absolute alcohol $(20 \mathrm{ml})$ was injected directly into the crater. The area blanched immediately, and the bleeding stopped. The postoperative period was uneventful except that she had a swinging fever for five days. She was discharged on the eighth postoperative day. She remained well for 10 months but died 14 months after surgery of extensive hepatoma.

Case 2-A 27 year old man presented with severe epigastric pain, shock, and peritonism. Laparotomy showed a $10 \mathrm{~cm}$ tumour at the dome of the right lobe of the liver. It had ruptured and was bleeding; $2 \cdot 5$ litres of blood was drained from the peritoneal cavity. There was also a $5 \mathrm{~cm}$ tumour in the left lobe. Alcohol $(50 \mathrm{ml})$ was injected into the ruptured tumour. Bleeding was controlled. He had low grade fever for five days postoperatively and was discharged on the eighth postoperative day. He died seven weeks later of disseminated carcinomatosis and liver failure.

Case 3-A 53 year old man who was known to have a hepatoma suddenly developed severe abdominal pain and shock. At laparotomy an $8 \mathrm{~cm}$ ruptured hepatoma with profuse bleeding was found. The liver was severely cirrhotic. Ligation of the hepatic artery slowed but did not stop the bleeding. Absolute alcohol $(40 \mathrm{ml})$ was injected into the lesion, and the haemorrhage stopped. He had swinging fever and a tachycardia for two days after the operation. He was discharged 21 days after operation. There was no evidence of rebleeding. He returned with disseminated

carcinomatosis four weeks later and died seven weeks after the episode of bleeding.

\title{
Comment
}

Resection of the affected lobe of the liver has been recommended as the treatment of choice for a ruptured hepatoma whenever possible. ${ }^{1}$ Unfortunately, few patients are suitable candidates for resection because either the tumour is too extensive or the liver is too cirrhotic. Ligation of the hepatic artery stops the bleeding but is associated with a mortality from liver failure of $50 \% .^{2}$ In suitable patients angiographic embolisation can stop the bleeding without an operation. ${ }^{3}$ This, however, requires a highly skilled radiologist, who may not be readily available at all hours in all hospitals.

Endoscopic injection of alcohol has been used to stop bleeding from oesophageal varices and peptic ulcers. ${ }^{4}$ Absolute alcohol stops bleeding by a process of dehydration and fixation of the tissues followed by thrombosis of the blood vessels. Percutaneous injection of alcohol under ultrasonographic control has been used successfully to destroy hepatocellular carcinomas. ${ }^{5}$

In case 1 resection was not possible because the tumour straddled both lobes and ligation of the hepatic artery was not feasible because of infiltration of the porta hepatis. As no effective alternative was available we injected alcohol. Encouraged by the outcome in this patient we used the same method for the two other patients. In case 2 the bilobar tumour was not suitable for resection, and in case 3 the bleeding was not controlled after ligation of the hepatic artery. Injection of absolute alcohol into the lesion stopped the haemorrhage in both patients.

Intralesional injection of alcohol is cheap, does not require any special skill, and should be possible in any operating theatre. It is a useful treatment for this challenging condition.

1 Ong GB, Taw JL. Spontaneous rupture of hepatocellular carcinoma. Br Med $\mathcal{J}$ 1972;iv: 146-9.

2 Chearanai O, Plengvanit U, Asavanich C, Damrongsak D, Sindhvananda K, Boonyapisit S. Spontaneous rupture of primary hepatoma: report of 63 cases with particular reference to the pathogenesis and rationale treatment by hepatic artery ligation. Cancer 1983;51:1532-6.

3 Hirai K, Kawazoe Y, Yamashita K, et al. Transcatheter arterial embolization for spontaneous rupture of hepato-cellular carcinoma. Am $\mathcal{f}$ Gastroenterol 1986;81:275-9.

4 Sugawa C, Fujita Y, Ikeda T, Walt AJ. Endoscopic hemostasis of bleeding of the upper gastrointestinal tract by local injection of ninety-eight per cent the upper gastrointestinal tract by local injection of nis

5 Shiina S, Yasuda $\mathrm{H}$, Muto $\mathrm{H}$, et al. Percutaneous ethanol injection in the Shiina S, Yasuda H, Muto H, et al. Percutaneous ethanol injection in the
treatment of liver peoplasms. American fournal of Radiology 1987;147: $949-52$

(Accepted 14 fune 1990)

\section{Adjustment of insulin doses of diabetic patients during long distance flights}

Helsinki University Hospital, 00290 Helsinki, Finland

T Sane, MD, senior lecturer, third department

V A Koivisto, MD, senior lecturer, second deartment P Nikkanen, RN, diabetes nurse, third department R Pelkonen, MD, professor, third department

Correspondence to: Dr Sane.

BrMed f 1990;301:421-2

\section{T Sane, V A Koivisto, P Nikkanen, R Pelkonen}

Travelling across several time zones changes a patient's schedule for insulin injections. Changes in their insulin requirement may be a concern for travelling patients as only rough guidelines for such changes have been published.' We advised patients on a regimen in which they increased their dose of insulin when travelling west and decreased it when travelling east. We report on the success of this regimen in terms of their control of blood glucose concentration and hypoglycaemic episodes.

\section{Patients, methods, and results}

We studied 27 patients with type I diabetes. Twenty patients were studied on one round trip, three on five eastward flights only, and four on four westward flights only. The average flight time and shift in time zone were 10.6 and seven hours respectively.

When travelling westwards the patients used their normal insulin regimen until departure and then followed it according to the local time after landing. The additional hours due to the shift in time zone were covered with one or two injections of short acting insulin with meals on the plane. When travelling eastwards the patients caught flights that left between $5 \mathrm{pm}$ and $9 \mathrm{pm}$. After departure they took their normal 